\title{
Epidemiology and the prevention of occupational asthma
}

There are some who question the value of epidemiology in preventing occupational disease. Certainly, in the field of cancer epidemiology, latent intervals are long and results relate to the working conditions of previous generations so cannot be extrapolated to the present without good exposure data. But in conditions with a short latent interval, such as occupational asthma, epidemiological findings are more readily applicable to current work practices.

Parkes lists over 100 causes of occupational asthma without claiming completeness and many are used in several industries. ${ }^{1}$ Keskinen and her colleagues estimated that almost a quarter of the Finnish working population was exposed in 1976 to agents known to cause asthma. ${ }^{2}$ She related the 80 new cases of occupational asthma registered in the Finnish Occupational Diseases Register in 1976 to the population exposed to these agents. This was estimated at 492500 , giving a crude annual incidence rate of $0 \cdot 2 / 1000$. She later reported an increase in registered cases to 156 in $1981 .{ }^{3}$ Keskinen's figures are likely to be considerable underestimates, because occupational asthma is commonly missed. Several cross sectional surveys have shown high prevalence rates of asthma in specific occupational groups. An early example was the survey by Hunter et al of platinum refinery workers in which $46 \%$ had asthma. ${ }^{4}$ Outbreaks of asthma in the detergent industry followed the introduction of proteolytic enzymes in the 1960s and cross sectional surveys reported asthma in $40-50 \%$ of workers. ${ }^{56}$ Recently, $2 \%$ of new laboratory workers were reported to develop asthma caused by animals during their first year of employment. ${ }^{7}$

Patients with occupational asthma often describe severe symptoms and clearly there is a risk of death in an acute attack. There is also a risk of chronic disability. Several series of patients have been followed up after leaving the work which caused asthma; exposures included toluene diisocyanate (TDI), ${ }^{8}$ wood dust (Western red cedar), ${ }^{9}$ solder fumes, ${ }^{10}$ and crab processing. ${ }^{11}$ The studies consistently suggest that about half the patients report respiratory symptoms at follow up and show the characteristic physiological abnormality of asthma, airway hyper-responsiveness to inhaled histamine or methacholine. The development of chronic asthma is associated with delay in diagnosis ${ }^{9}$ and continued exposure after diagnosis. ${ }^{8}$

Occupational asthma is thus common and potentially disabling. Epidemiological studies can help prevention by: $(a)$ identifying the cause, $(b)$ relating the rate of occurrence to the degree of exposure to the causal agent, (c) identifying personal factors which increase the risk, and (d) evaluating preventive measures.

Describing the variation in the occurrence of disease by place and time is a time honoured epidemiological strategy that has been used to identify occupational causes of asthma. A cross sectional survey traced asthma in a steel coating plant to a modification introduced into the process some years previously. ${ }^{12}$ TDI was the cause and this was confirmed clinically by inhalation challenge tests, and also by a second survey after TDI was removed, at which time the asthmatic symptoms had improved and no new cases had developed.

There is little information on the exposure response relation. Conventional techniques for environmental assessment are not always appropriate or adequate. Complex, poorly characterised biological materials that cause asthma, such as flour dust, may be measured as total dust but this is a crude surrogate for allergen exposure because only a proportion of the dust is allergenic and this fraction may vary. Immunological techniques for estimating environmental allergen have been developed ${ }^{13}$ but they are semiquantitative and indirect, requiring reference to blood samples from patients known to have the relevant antibody. Simple chemicals may be measured by conventional methods but their sensitivity is normally aimed at detecting levels around control limits which apply to toxicity rather than allergy. Patients with asthma caused by TDI may show significant asthmatic responses on exposure to less than $0.001 \mathrm{ppm}^{14}$ and responses to solder fumes may be elicited after only a few breaths. ${ }^{15}$

The conventional assumption that intensity and duration of exposure are equivalent in causing disease is particularly questionable in occupational asthma. 
Short periods of high exposure are possibly more important than the equivalent "dose" accumulated at a lower exposure over a longer time. Weill and his colleagues have studied workers at a new TDI manufacturing plant. ${ }^{16}$ TDI was monitored continuously by paper tape and, on average, exposure was $0.002 \mathrm{ppm}$. At least 12 workers, $4 \%$ of the population, developed asthma over a five year period, nine in the first year. Half these cases had been exposed to spills of TDI, six were maintenance workers, one a laboratory worker, and only five process workers.

Epidemiological studies have often looked for personal factors associated with occupational asthma. Atopy, variously defined as a personal or family history of allergy or on skin tests with common aeroallergens, is associated, for example, with asthma caused by laboratory animals. This raises the possibility of pre-employment screening for atopy with the aim of excluding susceptible individuals from employment with animals. Slovak and Hill have followed up their survey of laboratory employees ${ }^{17}$ with an assessment of the predictive value of atopy (129-132). Their original survey of 146 workers detected 15 with asthma, of whom 12 were atopic on skin testing. About $30-50 \%$ of the general population, however, are atopic and only a minority develop occupational asthma. The predictive value of atopy for laboratory animal asthma is poor, in whatever way atopy is defined, and it is difficult to justify excluding atopic persons from employment. There are other objections to pre-employment screening for atopy. Occupational rhinitis, conjunctivitis, and urticaria, which are more common reactions to animals than asthma, are less closely associated with atopy. ${ }^{1718}$ The association with atopy is not consistent-for example, it is absent for asthma caused by Western red cedar. ${ }^{19} \mathrm{~A}$ screening programme may divert attention from improving the environment which causes asthma and encourage the attitude that asthma is a problem of susceptibility and a medical, rather than an environmental, issue.

Recent observations associating smoking with occupational asthma may offer scope for prevention. Some employers already offer encouragement and education on stopping smoking. I and my colleagues have noted that a group of seven patients with asthma caused by tetrachlorophthalic anhydride (TCPA) were all current smokers. ${ }^{20}$ At the same time, an association between smoking and occupational sensitisation was reported from Sweden in pharmaceutical workers exposed to ispaghula and in coffee workers. ${ }^{21}$ Smokers showed excesses of serum anti-ispaghula IgE antibody and of skin weal responses to raw coffee dust extract. When serum anti-TCPA IgE antibody was measured in a population exposed to TCPA it was found that the antibody was six times more common in current smokers than in former and nonsmokers. ${ }^{22}$ Atopy per se was not significantly associated with an IgE response to TCPA but interacted with smoking so that the highest antibody prevalence $\overline{\bar{\alpha}}$ $(16 \%$ of 31$)$ was in atopic smokers. None of 98 non-3 atopic non-smokers had antibody. Few of the reports $\stackrel{乛}{\circ}$ of earlier surveys reported smoking habits in relation $\Rightarrow$ to markers of occupational asthma, but smoking $\stackrel{\vec{P}}{+}$ enzyme detergent workers had excesses of respiratory음 symptoms ${ }^{6}$ and of skin weal responses against the enzyme $^{23}$; this observation was not emphasised at the $\frac{\bar{\sigma}}{\overrightarrow{0}}$ time, however. It has since been shown that smoking ${ }_{\propto}^{\mathbb{\Phi}}$ is associated with asthma in crab processors. ${ }^{24}$ Smoking is known to increase lung permeability in $\operatorname{man}^{25} \vec{\circ}$

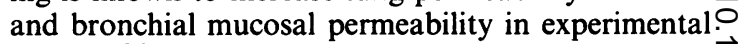
animals, ${ }^{26}$ leading us to speculate that smoking may $\vec{\omega}$ potentiate allergen access to submucosal immuno- $\sigma$ competent cells. ${ }^{22} 27$

Evaluative studies of preventive measures in 3 occupational health practice are rare, including those $\stackrel{+}{+}$ designed to prevent asthma. There are occasionaliv reports that the number of cases of asthma has fallen $\omega$ after environmental controls but these are difficult too assess. Usually multiple control measures, including improved ventilation, use of respiratory protection, 7 worker education, and pre-employment screening, are $\stackrel{\mathbb{D}}{2}$ applied so that it is impossible to know which, if any, of the package is most effective. Studies seldom define occupational asthma independently of knowledge of $\vec{\omega}$ exposure or control for changes over time, such as in $\infty$ number of subjects exposed.

Almost all the epidemiological studies so far hateo been cross sectional. Hospital patients with occupational asthma tend to have left the work which caused symptoms, sometimes on medical advice but

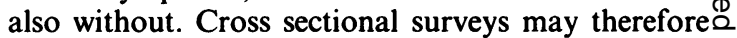
underestimate the prevalence of occupational asthma. $\overrightarrow{\overrightarrow{0}}$ The steel coating plant survey ${ }^{12}$ suggested that fewer 3 cases developed in the years immediately after TDI was introduced than in the years before the survey. As? the process had not changed over time this probablyo was explained by affected persons leaving the plant. $\frac{1}{3}$ The survey detected 21 cases of asthma (in 221 workers), but the true number could have been at least 3 . twice this if the number of cases a year was similar to that in the year preceding the survey. Cross sectional studies cannot show that a causal factor was presento before asthma developed. If, for example, more accidental chemical spills or family members with allergyo are reported by those with than without asthma it may simply mean that they have more reason to recallos these factors than people who are not concerned N about their health. Cross sectional surveys may alsoN be biased because cases of asthma remaining at work ${ }_{\sigma}^{\mathrm{\omega}}$ and included in a survey are the "survivors" and may differ in important respects from cases who have left.

It is notoriously difficult to define asthma. ${ }^{28}$ Symptoms of variable airway narrowing ${ }^{29}$ which are related ${ }_{\nabla}$ to work are readily recorded by questionnaire but for ${ }^{\circ}$ asthma there is nothing comparable to the Medical $\mathbb{\Phi}$ Research Council questionnaire which has been so $\frac{\mathcal{D}}{\mathbb{Q}}$ 
useful in studying chronic bronchitis. ${ }^{30}$ Research groups use their own questionnaires so comparison between surveys requires caution. Airway responsiveness to inhaled histamine or methacholine is correlated with the amount of medication needed to control symptoms of asthma ${ }^{31}$ with diurnal variability of lung function and reversibility of airway narrowing after a bronchodilator. ${ }^{32}$ As with other distributions, that of responsiveness in the general population is unimodal, ${ }^{33}$ so decisions as to what is "abnormal" are inevitably arbitrary. Moreover, responsiveness changes after exposure to allergen ${ }^{34}$ so a worker recently exposed may be very responsive but if he has avoided exposure, less responsive. The measurement of responsiveness takes some 15-30 minutes and different techniques are in use.

There is clearly much to be done in applying epidemiology to occupational asthma. We need a fresh approach to environmental measurement and simple, reliable case detection methods for surveys. Cross sectional surveys are useful for obtaining quick estimates of asthma frequency and suggesting causal associations but they should be followed by longitudinal studies. There is great potential for understanding occupational asthma through epidemiology, defining preventive strategies, and evaluating their effectiveness. As with any field of occupational epidemiology, success will need a multidisciplinary effort by epidemiologists, hygienists, and clinicians and cooperation between industry and research groups.

KATHERINE M VENABLES

Department of Occupational Medicine,

Cardiothoracic Institute,

Brompton Hospital,

London SW3 6HP, UK

\section{References}

1 Parkes WR. Occupational lung disorders. 2nd ed. London: Butterworths, 1982.

2 Keskinen H, Alanko H, Saarinen L. Occupational asthma in Finland. Clin Allergy 1978;8:569-79.

3 Keskinen $\mathbf{H}$. Epidemiology of occupational lung diseases: asthma and allergic alveolitis. In: Kerr JW, Ganderton MA, eds. Proceedings of XI International Congress of Allergology and Clinical Immunology. London: MacMillan, 1983:403-7.

4 Hunter D, Milton R, Perry KMA. Asthma caused by complex salts of platinum. $\mathrm{Br} J$ Ind Med 1945;2:92-8.

5 Newhouse ML, Tagg B, Pocock SJ, McEwan AC. An epidemiological study of workers producing enzyme washing powders. Lancet 1970;i:689-93.

6 Mitchell CA. Gandevia B. Respiratory symptoms and skin reactivity in workers exposed to proteolytic enzymes in the detergent industry. Am Rev Respir Dis 1971;104:1-12.

7 Davies GE. Thompson AV, Niewola Z, et al. Allergy to laboratory animals: a retrospective and a prospective study. $\mathrm{Br} J$ Ind Med 1983;40:442-9.

8 Paggiaro PL, Loi AM, Rossi O, et al. Follow-up study of patients with respiratory disease due to toluene diisocyanate (TDI). Clin Allergy 1984;14:463-9.

9 Chan-Yeung M, Lam S, Koener S. Clinical features and natural history of occupational asthma due to Western red cedar (Thuja plicata). Am J Med 1982;72:411-5.

10 Burge PS. Occupational asthma in electronics workers caused by colophony fumes: follow-up of affected workers. Thorax
1982:37:348-53.

11 Hudson P, Cartier A, Pineau L, et al. Follow-up of asthma caused by crab and various agents. $J$ Allergy Clin Immunol 1985;76:682-8.

12 Venables KM, Dally MB, Burge PS, Pickering CAC, Newman Taylor AJ. Occupational asthma in a steel coating plant. $B r J$ Ind Med 1985;42:517-24.

13 Agarwal MK, Yungiger JW, Swanson MC, Reed CE. An immunochemical method to measure atmospheric allergens. J Allergy Clin Immunol 1981;68:194-200.

14 O'Brien IM, Newman Taylor AJ, Burge PS, Harries MG, Fawcett IW, Pepys J. Toluene di-isocyanate-induced asthma II. Inhalation challenge tests and bronchial reactivity studies. Clin Allergy 1979;9:7-15.

15 Burge PS, Harries MG, O'Brien IM, Pepys J. Respiratory disease in workers exposed to soldier flux fumes containing colophony (pine resin). Clin Allergy 1978;8:1-14.

16 Weill H, Butcher B, Dharmarajan V, et al. Respiratory and immunologic evaluation of isocyanate exposure in a new manufacturing plant. Cincinnati: US Department of Health and Human Services, 1981. (NIOSH technical report.)

17 Slovak AJM, Hill RN. Laboratory animal allergy: a clinical survey of an exposed population. Br J Ind Med 1981;38:38-41.

18 Cockroft A, Edwards J, McCarthy P, Andersson N. Allergy in laboratory animal workers. Lancet 1981;ii:827-30.

19 Chan-Yeung M. Immunologic and non-immunologic mechanisms in asthma due to Western red cedar (Thuja plicata). $J$ Allergy Clin Immunol 1982;70:32-7.

20 Howe W, Venables KM, Topping MD, et al. Tetrachlorophthalic anhydride asthma: evidence for specific IgE antibody. J Allergy Clin Immunol 1983;71:5-11.

21 Zetterstrom O, Osterman K, Machado L, Johansson SGO. Another smoking hazard: raised serum IgE concentration and increased risk of occupational allergy. Br Med J 1981;283:1215-7.

22 Venables KM, Topping MD, Howe W, et al. Interaction of smoking and atopy in producing specific IgE antibody against a hapten protein conjugate. $\mathrm{Br}$ Med $J$ 1985;290:201-4.

23 Greenberg M, Milne JF, Watt A. A survey of workers exposed to dusts containing derivatives of Bacillus subtilis. Br Med J 1970;ii:629-33.

24 Cartier A, Malo J-L, Forest F, et al. Occupational asthma in snow crab-processing workers. $J$ Allergy Clin Immunol 1984;74:261-9.

25 Jones JG, Minty BD, Royston JP. Carboxyhaemoglobin and pulmonary epithelial permeability in man. Thorax 1983;38:129-33.

26 Hulbert WC, Walker DC, Jackson A, Hogg JC. Airway permeability to horseradish peroxidase in guinea pigs: the repair phase after injury by cigarette smoke. Am Rev Respir Dis 1981;123:320-6.

27 Anonymous. Smoking, occupation and allergic lung disease (Editorial). Lancet 1985;ii:965.

28 Porter R, Birch J, eds. Identification of asthma. Edinburgh: Churchill Livingstone. 1971. (Ciba foundation study group No 38.)

29 Scadding JG. Meaning of terms in broncho-pulmonary disease. Br Med J 1963;ii:1425-30.

30 Medical Research Council. Questionnaire on respiratory symptoms. London: Medical Research Council, 1976.

31 Cockcroft DW, Killian DN, Mellon JJA, Hargreave FE. Bronchial reactivity to inhaled histamine: a method and clinical survey. Clin Allergy 1977;7:235-43.

32 Ryan G, Lattimer KM, Dolovich J, Hargreave FE. Bronchial responsiveness to histamine: relationship to diurnal variation of peak flow rate, improvement after bronchodilator and airway calibre. Thorax 1982;37:423-9.

33 Cockcroft DW, Berscheid BA, Murdock KY. Unimodal distribution of bronchial responsiveness to inhaled histamine in a random human population. Chest 1983;83:751-4

34 Cartier A. Thomson NC, Roberts R, Hargreave FE. Allergeninduced increase in bronchial responsiveness to histamine: relationship to the late asthmatic response and change in airway calibre. J Allergy Clin Immunol 1982;70:170-7. 